\title{
Helicobacter pylori in cathartic stools of subjects with and without cimetidine-induced hypochlorhydria
}

\author{
Thomas Haggerty, ${ }^{1}$ Haim Shmuely ${ }^{1}$ and Julie Parsonnet ${ }^{1,2}$
${ }^{1}$ Division of Infectious Diseases and Geographic Medicine, Department of Medicine, School of Medicine, Stanford University, Stanford, CA 94305-5107, USA
${ }^{2}$ Division of Epidemiology, Department of Health Research and Policy, Stanford University, Stanford, CA, USA

Correspondence

Thomas Haggerty

tdhaggerty@stanford.edu

\begin{abstract}
We previously identified viable Helicobacter pylori in stools from asymptomatic hosts. We now report whether a decrease in gastric acidity enhances faecal shedding. Sixteen asymptomatic $H$. pylori-positive patients underwent two separate days of phosphosoda-induced diarrhoea, both with normal gastric acidity and under hypochlorhydric conditions induced with the $\mathrm{H} 2$-blocker cimetidine. Stool samples were collected for culture to determine the presence of viable H. pylori. Five of the 16 patients gave positive cultures with at least one stool from both normal $\mathrm{pH}$ and cimetidine-induced hypochlorhydria. Four were negative for all samples with both. Six gave positive stools only after cimetidine treatments, while one gave positive samples with normal $\mathrm{pH}$ but not with cimetidine (two-tailed $P$ value, 0.13 ; McNemar test). These numbers show a trend suggesting that cimetidine-induced hypochlorhydria increases shedding of viable $H$. pylori.
\end{abstract}

Received 18 March 2002

Accepted 19 August 2002

\section{INTRODUCTION}

Helicobacter pylori causes gastritis, peptic ulcers and gastric cancer. Although found in half of the world's population, the organism's exact mode of transmission remains uncertain. In a previous study (Parsonnet et al., 1999), we uniformly cultured H. pylori from subjects' vomitus and from $50 \%$ of cathartic stools but not from normal stools. This led us to postulate that $H$. pylori is excreted during episodes of gastroenteritis. In ferrets, Helicobacter mustelae appears to be shed more readily when the stomach is hypochlorhydric (Fox et al., 1993). In this follow-up study, we assessed whether increasing gastric $\mathrm{pH}$ before and during simulated gastroenteritis increased shedding of viable organisms in the stools of $H$. pylori-infected volunteers.

\section{METHODS}

Patients. Healthy $H$. pylori-infected volunteers were recruited as described previously (Parsonnet et al., 1999). Seventeen H. pylori IgGseropositive subjects with positive $\mathrm{C}^{13}$-urea breath tests (Meretek Corp.) agreed to return on two separate occasions for study. On one occasion, subjects were given Fleet's phosphosoda orally and all subsequent stools were collected and processed. On the other occasion, administration of Fleet's phosphosoda (C. B. Fleet Co.) was preceded by 2 weeks of cimetidine ( $400 \mathrm{mg}$ p.o. bid) (GlaxoSmithKline). Subjects then began to receive cimetidine $\left(38 \mathrm{mg} \mathrm{h}^{-1}\right)$ intravenously prior to phosphosoda administration and throughout the stool collection period that followed. Serum cimetidine levels were assessed prior to intravenous administration. Twelve subjects had previously partici- pated in an experiment of vomiting and H. pylori (Parsonnet et al., 1999). From these 12 subjects, there are data on vomitus $\mathrm{pH}$ in the absence of cimetidine use.

Techniques. All stool samples from both parts of the study were cultured for H. pylori as described previously (Parsonnet et al., 1999). Briefly, subjects were administered $45 \mathrm{ml}$ sodium phosphate solution in $90 \mathrm{ml}$ water followed by $720 \mathrm{ml}$ water followed by an $8 \mathrm{~h}$ collection of all stools, which were transported immediately to the laboratory.

Stool samples were diluted to a $20 \%$ suspension in PBS and sieved through a $250 \mu \mathrm{m}$ strainer. A $200 \mu \mathrm{l}$ portion was plated on $5 \%$ sheepblood trypticase soy agar supplemented with polymyxin $B\left(3.3 \mu \mathrm{g} \mathrm{ml}^{-1}\right)$, amphotericin $\mathrm{B}\left(50 \mu \mathrm{g} \mathrm{ml}^{-1}\right)$, bacitracin $\left(200 \mu \mathrm{g} \mathrm{ml}^{-1}\right)$, nalidixic acid $\left(10 \cdot 7 \mu \mathrm{g} \mathrm{ml}^{-1}\right)$ and vancomycin $\left(100 \mu \mathrm{g} \mathrm{ml}^{-1}\right)$. The plates were incubated microaerophilically at $37^{\circ} \mathrm{C}$ for up to 10 days.

Suspicious colonies were confirmed as $H$. pylori first with positive oxidase, catalase and urease tests and then with PCR using H. pylorispecific primers within the 16S rRNA gene (Parsonnet et al., 1999). When possible, colonies were counted and an estimate of the number of c.f.u. $\mathrm{g}^{-1}$ stool was determined.

\section{RESULTS}

Successful catharsis was defined as three or more loose or watery stools with an interval of less than $1 \mathrm{~h}$ between each stool passed. The mean number of stools per subject from both arms of the study was $6 \cdot 7$ (SD 2.3) and was similar with and without cimetidine pre-treatment $(P=0 \cdot 6$; paired $t$ test). Detectable levels of serum cimetidine ranged from 0.06 to $0.51 \mu \mathrm{g} \mathrm{ml}^{-1}$. Serum levels of cimetidine were below 
detectable levels for four patients (20,57, 62 and 135) and serum was lost to incorrect tests by an outside lab for patients 33 and 106.

Of the 16 subjects with successful catharsis, six had positive cultures with but not without cimetidine (Table 1). In one subject, the reverse was true (the subject's stools grew $H$. pylori without but not with cimetidine). The remaining nine subjects had either negative (four) or positive (five) stools on both occasions. Among the latter group, for three of the five subjects $(20,106$ and 135), we were able to count c.f.u. from all samples. Uniformly, in these three paired sets, counts were higher in the cimetidine experiment. Thus, cimetidine tended to increase the proportion of subjects who shed $H$. pylori in stools from 38 to $69 \%$ (two-tailed $P$ value, $0 \cdot 13$; McNemar test) and to increase the quantity of $H$. pylori shed.

\section{DISCUSSION}

In this study, we found preliminary evidence that hypochlorydria does increase $H$. pylori transmission in humans. Methodological issues, however, limited our ability to support this conclusion definitively. Firstly, we didn't measure gastric $\mathrm{pH}$ directly. Three of the initial 12 subjects studied had elevated vomitus $\mathrm{pH}$ prior to initiation of cimetidine. In this potentially hypochlorhydric group, there

Table 1. Results of $H$. pylori culture from stools of subjects both with and without cimetidine pre-treatment

Numbers or ' + ' represent stools that yielded H. pylori. Presence of $H$. pylori is scored as: numbers, c.f.u. per 40 mg (one plate) of cultured stool; + , positive culture, c.f.u. not counted; -, negative culture; NC, not cultured (stool sample could not be cultured for technical reasons).

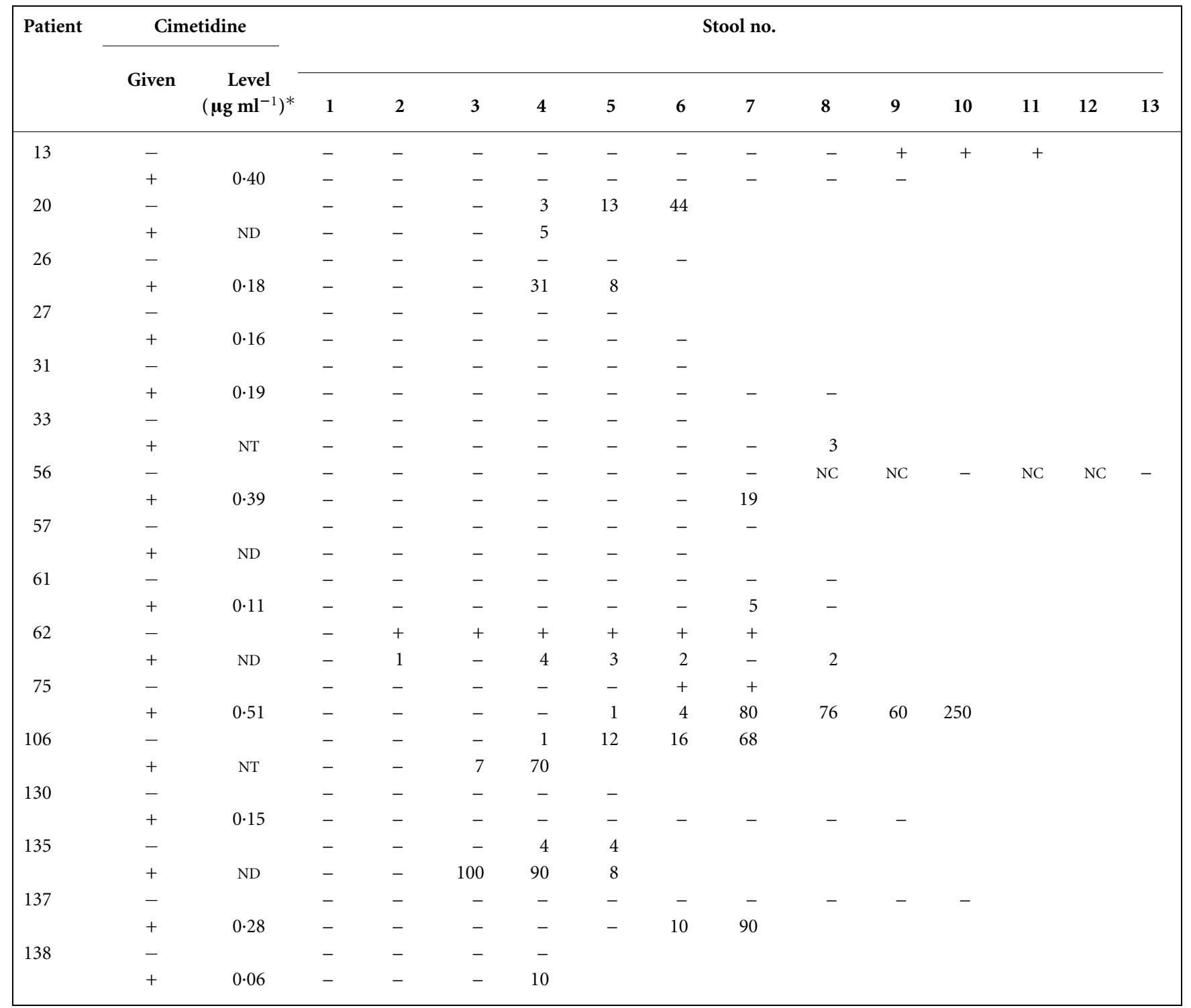

${ }^{*} \mathrm{ND}$, Not detected; NT, not tested. 
may have been little effect of added cimetidine. Moreover, we chose to use cimetidine rather than a proton pump inhibitor for this experiment because we were concerned that the latter, via their antimicrobial effects, might limit growth of $H$. pylori. However, cimetidine only blocks acid secretion modestly. In a setting where cimetidine levels in 14 patients were below therapeutic range prior to administration of the cathartic, acid suppression may not have been sufficient to cause changes in $H$. pylori shedding. Our subjects were also not randomized to the order in which they underwent the two experiments - no cimetidine vs cimetidine. Most received cimetidine the second time they underwent the experiment. Although improved skill in culturing from stools over time could theoretically account for some of the change observed, given the considerable experience in our laboratory with the technique as well as the blinding of laboratory personnel to treatment arm, we deem this possibility unlikely. Most importantly, however, our sample size was small. Since only 10 subjects did not excrete $H$. pylori in the initial pre-cimetidine phase, the opportunity to identify a change was limited. We felt, however, that the amount to be learned by enrolling more patients in this particular study design did not warrant more recruitment. Instead, we thought the hypothesis would be better addressed in experiments that assess $H$. pylori shedding and gastric acidity directly in naturally occurring diarrhoeal diseases.

Despite the above caveats, we believe the increase in $H$. pylori shedding observed during cimetidine-catharsis supports a cunning transmission cycle for the organism. H. pylori is causally linked with hypochlorhydria in two settings: during acute infection (Gledhill et al., 1985; Graham et al., 1988) and after years of infection when atrophic gastritis has developed (el-Omar et al., 1997). Hypochlorhydria, in turn, enhances the likelihood of developing diarrhoeal illness by allowing acid-sensitive gastrointestinal pathogens to traverse the stomach and enter the intestine (Buchin et al., 1980; Nalin et al., 1978). During diarrhoea, particularly with hypochlorhydria, $H$. pylori is shed, permitting the cycle to repeat itself.
The potential increase in transmission related to hypochlorhydria must outweigh the effects of decreased $H$. pylori colonization observed in individual patients with natural hypochlorhydria (el-Omar et al., 1997). This cycle may also help to explain why $H$. pylori prevalence is decreasing; as diarrhoeal diseases abate as a result of socio-economic development, H. pylori should decrease in parallel.

\section{ACKNOWLEDGEMENTS}

This study was supported by Health and Human Services grant M01RR00070 for the General Clinical Research Center Program and by grant KD53689 from the NIH, National Institute of Diabetes and Digestive and Kidney Diseases. We would like to thank Ms Rosario Villacorta and Dr Marcos Borba de Arruda for technical assistance with this project.

\section{REFERENCES}

Buchin, P. J., Andriole, V. T. \& Spiro, H. M. (1980). Salmonella infections and hypochlorhydria. J Clin Gastroenterol 2, 133-138.

el-Omar, E. M., Oien, K., El-Nujumi, A., Gillen, D., Wirz, A., Dahill, S., Williams, C., Ardill, J. E. \& McColl, K. E. (1997). Helicobacter pylori infection and chronic gastric acid hyposecretion. Gastroenterology 113 , 15-24.

Fox, J. G., Blanco, M. C., Yan, L., Shames, B., Polidoro, D., Dewhirst, F. E. \& Paster, B. J. (1993). Role of gastric pH in isolation of Helicobacter mustelae from the feces of ferrets. Gastroenterology 104, 86-92.

Gledhill, T., Leicester, R. J., Addis, B., Lightfoot, N., Barnard, J., Viney, N., Darkin, D. \& Hunt, R. H. (1985). Epidemic hypochlorhydria. Br Med J (Clin Res Ed) 290, 1383-1386.

Graham, D. Y., Alpert, L. C., Smith, J. L. \& Yoshimura, H. H. (1988). Iatrogenic Campylobacter pylori infection is a cause of epidemic achlorhydria. Am J Gastroenterol 83, 974-980.

Nalin, D. R., Levine, M. M., Rhead, J., Bergquist, E., Rennels, M., Hughes, T., O'Donnel, S. \& Hornick, R. B. (1978). Cannabis, hypochlorhydria, and cholera. Lancet ii, 859-862.

Parsonnet, J., Shmuely, H. \& Haggerty, T. (1999). Fecal and oral shedding of Helicobacter pylori from healthy infected adults. JAMA 282, 2240-2245. 